\title{
Research on Promotion of Consumers' Application of After Service in Online Shopping Based on Evolutionary Game Theory-- Introduction of Smart Contract
}

\author{
Hongzhen $\mathrm{Lei}^{1}$, Di Lu ${ }^{1, *}$, HongHong Zhang ${ }^{1}$ \\ ${ }^{1}$ Shaanxi Normal University, International Business School, 710119, Xi'an
}

\begin{abstract}
In order to research how to promote online shopping consumers' application of after service, build an evolutionary game model of both consumers and e-stores. This paper introduces the variables of supervision and punishment, tries to introduce the smart contract as a powerful service guarantee, and analyzes the influence relationship of variables between the two players and their strategic choices. This paper analyzes the ESS of the system when the relationship among smart contract, revenue, supervision and punishment meets 8 different conditions. Finally, giving suggestions to optimize the after service in online shopping according to the results.
\end{abstract}

\section{INTRODUCTION}

Recently, online transactions have been developing rapidly. In 2019, online retail sales increased from $10.8 \%$ to $20.7 \%$ in $2015^{[1]}$. However, while bringing convenience to people's lives, e-commerce platforms aggravate the problem of information asymmetry between buyers and sellers ${ }^{[2]}$.

Information asymmetry in online shopping always leads to service failure, and timely, effective service recovery is the only way to recover consumers ${ }^{[3]}$. However, merchants often miss the opportunity of service recovery because they are not aware of service failure ${ }^{[4]}$. Among consumers who do not complain directly to merchants, some choose to keep silent (reducing loyalty), while others choose to complain indirectly (passing negative word of mouth) ${ }^{[5-6]}$. As for the service failure of online shopping, the process of applying for after service is the process of complaining. Hogreve and Gremler mentioned that $95 \%$ of consumers would not complain after service failure ${ }^{[7]}$, which would not only fail to get the desired utility on themselves, but also cause businesses to lose the recovery opportunity.

Service guarantee can promote consumers to complain by reducing their risk perception ${ }^{[8]}$. As the core of blockchain technology, smart contract is open, observable, verifiable and unchangeable, which not only helps to alleviate information asymmetry between consumers and merchants, but also can be applied to online shopping as a powerful service guarantee. Therefore, this paper considers the supervision by the ecommerce platform and the fraudulent behavior of consumers and merchants, introduces smart contract as the service guarantee, establishes an evolutionary game model between merchants and consumers, and analyzes the strategic choice of consumers' after-sales behavior when service failure occurs. According to the analysis, suggestions are put forward to improve the probability of consumers applying for after service, optimize the after service process in online shopping.

\section{LITERATURE REVIEW}

Due to the information asymmetry in online shopping, service failure often occurs. Customers divide service failure into three types: consequential failure, procedural failure and interactive failure[9]. It is not difficult to see that the failure in online shopping is a consequential failure. Therefore, in online shopping, consumers often attribute the failure to merchants [10] and thus make the following three actions: unresponsive exit, appeal to the company and negative word of mouth [11]. Only by appealing to the company can the customer give the merchant a chance to recove the situation, while the other two behaviors will bring losses to the merchant.

In online shopping, the process of applying for after service is the process of appealing to the company, and the process of providing after service is the process of service recovery. However, with the development of ecommerce, network after-sales has become a bottleneck restricting the development of online shopping ${ }^{[12]}$. College students often gave up after-sales behaviors due to the high cost of rights protection and the unequal relationship between buyers and sellers in after-sales service ${ }^{[13]}$. Therefore, how to urge customers to apply for after-sales service is a important problem.

Existing studies have shown that service guarantee, as one of the prior service recovery, can help customers to complain to merchants bravely ${ }^{[8]}$. Some scholars believe that service guarantee is the commitment made by enterprises to the service quality that customers will

$\overline{{ }^{*} \text { Corresponding author: Di Lu. E-mail: } 1 d 961010 @ 163 . c o m}$ 
obtain ${ }^{[14]}$. Some scholars also regard service guarantee as a recovery scheme proposed by enterprises for service failure ${ }^{[15]}$. These studies show that service guarantee can attract customers and deal with service failures by delivering quality signals through promises.

According to "signaling-theory", an effective service guarantee can convey product quality and after-sales information to consumers, reduce consumers' perceived risk, improve perceived value, and mitigate the impact of information disadvantage on consumer behavior ${ }^{[16]}$. Hart pointed out that unconditional, easy to understand and communicate, meaningful, easy to use and easy to perform are five important characteristics of effective service guarantee ${ }^{[17]}$. Jin Liyin further pointed out that content credibility, commitment adequacy and conditionality have a significant impact on customers' risk perception, while content credibility, commitment adequacy and convenience have a significant impact on customers' value perception ${ }^{[8]}$.

However, in addition to the above factors, online shopping also exists fraud on both sides. Some scholars pointed out that not every customer would use the service guarantee to seek compensation, and there would also be customers abusing the service guarantee to seek personal gain ${ }^{[18]}$. Although consumers are at an information disadvantage, they are still likely to take advantage of the poor information of online shopping to cheat merchants, such as insurance fraud.

Studies have shown that the application of smart contract can solve this problem when both parties cannot fully trust each other ${ }^{[19]}$. Smart contract is a core concept in blockchain technology, and it is a computable transaction protocol of the contract terms based on blockchain technology ${ }^{[20]}$. It is characterized by certainty, consistency, terminability, verifiability, decentralization, high efficiency, real-time performance and low cost, etc. ${ }^{[21]}$. In the field of marketing, the characteristics of smart contract can be used as an objective and effective service guarantee different from the traditional form of e-store service recovery to improve the value perception of consumers and reduce the risk perception.

To sum up, there are still some deficiencies in the existing studies. Firstly, few researches have discussed the after-sale service of online shopping as a form of customer complaint; secondly, few scholars have introduced platform supervision into the evolutionary game analysis between consumers and merchants in the process of after-sales service; thirdly, few scholars have discussed the influence of the form of service guarantee in online shopping on consumers' complaining behavior. Therefore, this paper introduces intelligent contract as a new form of service guarantee in online shopping, and takes into account the supervision and punishment of fraudulent behaviors of both parties in after-sales service by e-commerce platform, and conducts an evolutionary game analysis on the behaviors of consumers and merchants in the process of after-sales service.

\section{ANALYSIS OF GAME PROCESS BETWEEN CONSUMERS AND E-STORE}

\subsection{Construction of evolutionary game model}

Based on the fact that consumers have already bought the goods, this paper takes the smart contract as a kind of service guarantee, and constructs an evolutionary game model of after-sales behavior between the two parties. Suppose a merchant has two strategies: using smart contracts and not using smart contracts. There are two strategies for consumers: applying for after-sales service and not applying for after-sales service.

The hypotheses of the evolutionary game model are as follows:

Hypothesis 1: When a consumer buys a good, the consumption is. The dissatisfaction degree of the consumer to the goods is $r(0 \leq r \leq 1)$, which means the distance of perceived utility to expected degree of consumers, so the utility loss is $\mathrm{rP}$. The revenue obtained by the merchant is $\mathrm{P}$, and the product cost is $\mathrm{Q}$.

Hypothesis 2: When consumers apply for after-sales services, the application cost is $a_{i} C_{1}(i=1$ or 2$)$, is the application cost coefficient when merchants use smart contracts, is that when merchants do not use smart contracts. When the merchants receive the after-sale application, there will be processing $\operatorname{cost} b_{i} C_{2}(i=1$ or 2$)$, the meaning of $b_{i}$ is same as $a_{i}$. Due to the use of smart contract, communication cost and labor cost are saved. Therefore, it can be known that $a_{1}<a_{2}, b_{1}<b_{2}$.

Hypothesis 3: When merchants use smart contracts, there is a cost $C_{3}$, and because of its strong service guarantee feature, it will reduce consumers' risk perception and bring potential benefits $\mathrm{W}$ to merchants.

Hypothesis 4: When merchants decide whether process the after-sales or not for consumers, there is a rationality coefficient $k_{i}$ ( $i=1$ or 2$), k_{1}$ is for condition that merchants using smart contract, and $k_{2}$ for that merchants not using smart contract, as its judgment. When consumer apply after-sales service, there is an integrity coefficient $m_{i}(i=1$ or 2$)$, the usage scenario of is $m_{i}$ the same as $k_{i}$, as their degree of integrity. When $m_{i} \geq k_{i}$, merchants will process after-sales service for consumers; otherwise, merchants will refuse consumers' application. Sectional function $f\left(m_{i}, k_{i}\right)$ is denoted as, using to express the willingness of merchants to deal with after-sales application $\left(0 \leq m_{i} \leq 1,0 \leq k_{i} \leq 1\right)$.

$$
f_{i}=\left\{\begin{array}{c}
{[\mathrm{mi}-\mathrm{ki}], \mathrm{mi} \neq \mathrm{ki}} \\
1, \mathrm{mi}=\mathrm{ki}
\end{array}\right.
$$

Hypothesis 5: When merchants do not use smart contract, there is a condition that merchants refuse to compensate for consumers (fraudulent behavior). $\chi$ is assumed as the probability of merchants willing to compensate for consumers $(0 \leq \lambda \leq 1)$. What's more, assuming that if merchants refuse to compensate for consumers, consumers would inform against merchants to platforms, and the probability of processing tip-off by platform is $\beta(0 \leq \beta \leq 1)$. If platform deal with the tip-off, it would give consumers some compensation to make up for the loss of consumers. Assuming that the 
compensation is the same as consumers' utility loss, and the punishment of merchants is $(H>r F)$.

Hypothesis 6: The probability of consumers applying for after-sales service is $x$, and that of no application is $1-x$. The probability of merchants using smart contract is $y$, and that of no usage is $1-y$.

Table 1. The payoff matrix of consumers and merchants

\begin{tabular}{|c|c|c|c|}
\hline & \multicolumn{2}{|c|}{ Merchants } \\
\hline & & $\begin{array}{c}\text { Using } \\
\text { smart } \\
\text { contract }(y)\end{array}$ & $\begin{array}{l}\text { Not using smart } \\
\text { contract (1-y) }\end{array}$ \\
\hline \multirow{2}{*}{$\begin{array}{c}\text { consu } \\
\text { mers }\end{array}$} & $\begin{array}{l}\text { Applying for } \\
\text { after service } \\
\text { (x) }\end{array}$ & $\begin{array}{c}-r P-a_{1} C_{1}+f_{1} F \\
P-Q-b_{1} C_{2}-C_{3}+W-f_{1} F\end{array}$ & $\begin{array}{l}-r P-a_{2} C_{1}+\lambda f_{2} r P+(1-\lambda) f_{2} \beta P P \\
P-Q-b_{2} C_{2}-\lambda f_{2} r P-(1-\lambda) f_{2} \beta H\end{array}$ \\
\hline & $\begin{array}{c}\text { Not } \\
\text { applying for } \\
\text { after service } \\
(1-x)\end{array}$ & $\begin{array}{c}-r F \\
P-Q-C_{3}+W\end{array}$ & $\begin{array}{l}-r P \\
P-Q\end{array}$ \\
\hline
\end{tabular}

\subsection{Path analysis of evolutionary game}

\subsubsection{Construction of revenue expectation function}

The expected benefits of consumers applying for after service is marked as $E_{11}$, and another one is marked as $E_{12}$. $E_{11}=y\left(-r P-a_{1} C_{1}+f_{1} r P\right)+(1-y)\left[-r P-a_{2} C_{1}+\lambda f_{2} r P+(1-\lambda) f_{2} \beta r P \mid\right.$ $E_{12}=y(-r P)+(1-y)(-r P)$

The expected benefits of merchants using smart contract is marked as $E_{21}$, and another one is marked as $E_{22}$. $E_{21}=x\left(P-Q-b_{1} C_{2}-C_{3}+W-f_{1} r P\right)+(1-x)\left(P-Q-C_{3}+W\right)$ $E_{22}=x\left[P-Q-b_{2} C_{2}-\lambda f_{2} r P-(1-\lambda) f_{2} \beta H\right]+(1-x)(P-Q)$

\subsubsection{Replicated dynamic equation}

Above all, we analyze the sectional function $f_{i}$ in different conditions. When merchants use smart contract as a service guarantee, the rationality of after service application is judged by the large data in blockchain. If consumers want to deceive merchants to acquire excess compensation, the application would not be passed.

Therefore, consumers would not to put forward unreasonable demands, and $f_{1}=1$ is always true. When merchants do not use smart contract, if consumers have fraudulent behavior, merchants would have two behaviors: one is compensating for consumers with higher degree, another one is refuse to deal with this application. At this time, merchants will use smart contract instead to avoid the tip-off, although the tip-off is useless because of consumers'dishonesty. Combined with the reality, consumers are always at information disadvantage, they are less likely to cheat, and merchants always ignore this unreasonable demand, we assume that $f_{2}=1$.

Considering the value of $f_{i}$, the replicated dynamic equations are as follow:

$$
\begin{aligned}
& F(x)=\frac{d x}{d t}=x(1-x)\left(E_{11}-E_{12}\right) \\
& \left.\left.\left.=x(1-x) \cup\left(a_{2}-a_{1}\right) C_{1}+r P-[\lambda+(1-\lambda)]\right] P P\right\}-a_{2} C_{1}+[\lambda+(1-\lambda)] p\right] P Y \\
& F(y)=\frac{d y}{d t}=y(1-y)\left(E_{21}-E_{2}\right)=y(1-y)\left\{x\left[\left(b_{2}-b_{1}\right) C_{2}-(1-\lambda)(r P-\beta H)\right]-C_{3}+W\right\}
\end{aligned}
$$

\subsubsection{Analysis of game evolution strategy}

(1) Asymptotic stability analysis of consumers.

Combined function (1), let $F(x)=0$, we get that $x^{*}=0, x^{*}=1, y^{*}=\frac{a_{2} C_{1}-[\lambda+(1-\lambda) \beta] r P}{\left(a_{2}-a_{1}\right) C_{1}+r P-[\lambda+(1-\lambda) \beta]}$

$\frac{\partial F(x)}{\partial x}=(1-2 x)\left(y\left\{\left(a_{2}-a_{1}\right) C_{1}+r P-[\lambda+(1-\lambda) \beta] r P\right\}-a_{2} C_{1}+[\lambda+(1-\lambda) \beta] r P\right\rangle$

According to the stability theorem of replicated dynamic equation, when $F(x)=0$ and $\frac{\partial F(x)}{\partial x}<0, x^{*}$ is the evolutionary stability strategy.

1) When $y^{*}=\frac{a_{2} C_{1}-[\lambda+(1-\lambda) \beta] r P}{\left(a_{2}-a_{1}\right) c_{1}+r P-[\lambda+(1-\lambda) \beta] r P}, F(x)=0$ is always true, and all levels are stable.

2) When $y \neq \frac{a_{2} C_{1}-[\lambda+(1-\lambda) \beta] r P}{\left(a_{2}-a_{1}\right) C_{1}+r P-[\lambda+(1-\lambda) \beta] r P}$ and $\lambda+(1-\lambda) \beta>\frac{a_{2} C_{1}}{r P}$, $\left.\frac{\partial F(x)}{\partial x}\right|_{x=0}>0,\left.\frac{\partial F(x)}{\partial x}\right|_{x=1}<0, x=1$ is the equilibrium point.

3) When $a_{1} C_{1}>r P,\left.\frac{\partial F(x)}{\partial x}\right|_{x=0}<0,\left.\frac{\partial F(x)}{\partial x}\right|_{x=1}>0, x=0$ is the equilibrium point.

4) When $x+(1-x) \beta<\frac{a_{2} C_{1}}{r P}$ and $a_{1} C_{1}<r P$. And when $y<\frac{a_{2} C_{1}-[\lambda+(1-\lambda) \beta] r P}{\left(a_{2}-a_{1}\right) C_{1}+r P-[\lambda+(1-\lambda) \beta] r F},\left.\frac{\partial F(x)}{\partial x}\right|_{x=0}<0,\left.\frac{\partial F(x)}{\partial x}\right|_{x=1}>0, x=0$ is the equilibrium point. On the contrary, when $y>\frac{a_{2} C_{1}-[\lambda+(1-\lambda) \beta] r P}{\left(a_{2}-a_{1}\right) C_{1}+r P-[\lambda+(1-\lambda) \beta] r F}, \chi=1$ is the equilibrium point

(2) Asymptotic stability analysis of merchants.

Combined function (2), let $F(y)=0$, we get that $y^{*}=0, y^{*}=1, x^{*}=\frac{C_{3}-W}{\left(b_{2}-b_{1}\right) C_{2}-r P+\not r P+(1-\lambda) \beta H}$. The deriv of $F(y)$ is:

$$
\frac{\partial F(y)}{\partial y}=(1-2 y)\left\{x\left[\left(b_{2}-b_{1}\right) C_{2}-(1-\lambda)(r P-\beta \mathrm{H})\right]-C_{3}+W\right\}_{(4)}
$$

According to the stability theorem of replicated dynamic equation, when $F(y)=0$ and $\frac{\partial F(y)}{\partial y}<0, y^{*}$ is the evolutionary stability strategy.

1) When $x^{*}=\frac{C_{3}-W}{\left(b_{2}-b_{1}\right) C_{2}-(1-\not)(r P-\beta \mathrm{H})}, F(y)=0$ is always true, and all levels are stable.

2) When $x \neq \frac{C_{3}-W}{\left(b_{2}-b_{1}\right) C_{2}-(1-\not)(r P-\beta \mathrm{H})}$, and when $\beta \mathrm{H}>\mathrm{rP}-\frac{\left(b_{2}-b_{1}\right) C_{2}}{1-\lambda}$ and $C_{3}<W,\left.\frac{\partial F(y)}{\partial y}\right|_{y=0}>0,\left.\frac{\partial F(y)}{\partial y}\right|_{y=1}<0, \quad y=1$ is the equilibrium point.

3) When $\beta \mathrm{H}<\mathrm{rP}-\frac{\left(b_{2}-b_{1}\right) C_{2}}{1-\lambda}$ and $C_{3}>W,\left.\frac{\partial F(y)}{\partial y}\right|_{y=0}<0$, $\left.\frac{\partial F(y)}{\partial y}\right|_{y=1}>0, y=0$ is the equilibrium point. In contrast to $2)$, merchants will not choose to use smart contract.

4) When $C_{3}>W$ and $\beta \mathrm{H}>\mathrm{rP}-\frac{\left(b_{2}-b_{1}\right) C_{2}}{1-\lambda}$. And when $\beta \mathrm{H}<\frac{b_{1} C_{2}+C_{3}-W+r P-b_{2} C_{2}-\lambda r F}{1-\lambda},\left.\frac{\partial F(y)}{\partial y}\right|_{y=0}<0,\left.\frac{\partial F(y)}{\partial y}\right|_{y=1}>0, y=0$ is the equilibrium point. When $\beta \mathrm{H}>\frac{b_{1} C_{2}+C_{3}-W+r P-b_{2} C_{2}-x_{r} F}{1-x}$, and when $x>\frac{C_{3}-W}{\left(b_{2}-b_{1}\right) C_{2}-(1-\lambda)(r P-\beta H)},\left.\frac{\partial F(y)}{\partial y}\right|_{y=0}>0,\left.\frac{\partial F(y)}{\partial y}\right|_{y=1}<0, y=1$ is the equilibrium point, in this condition, the expected punishment to merchants is higher. On the contrary, if $x<\frac{c_{3}-W}{\left(b_{2}-b_{1}\right) c_{2}-(1-x)(r P-\beta H)}, y=0$ is the equilibrium point, merchants choose the strategy of not using smart contract.

5) When $C_{3}<W$ and $\beta \mathrm{H}<\mathrm{rP}-\frac{\left(b_{2}-b_{1}\right) C_{2}}{1-\lambda}$. And when $\beta H>\frac{b_{1} C_{2}+C_{3}-W+r P-b_{2} C_{2}-\lambda r F}{1-\lambda},\left.\frac{\partial F(y)}{\partial y}\right|_{y=0}>0,\left.\frac{\partial F(y)}{\partial y}\right|_{y=1}<0, y=1$ is the equilibrium point. When $\beta \mathrm{H}<\frac{b_{1} C_{2}+C_{3}-W+r P-b_{2} C_{2}-\lambda r F}{1-x}$, if $x>\frac{C_{3}-W}{\left(b_{2}-b_{1}\right) C_{2}-(1-\lambda)(r P-\beta H)},\left.\frac{\partial F(y)}{\partial y}\right|_{y=0}<0,\left.\frac{\partial F(y)}{\partial y}\right|_{y=1}>0, y=0$ is the equilibrium point. On the contrary, if $x<\frac{C_{3}-W}{\left(b_{2}-b_{1}\right) C_{2}-(1-\gamma)(r P-\beta H)}, y=1$ is the equilibrium point, merchants choose the strategy of using smart contract. 
According to the above evolution stability condition, when the perceived risk of application is relatively high, decision-making of consumers is influenced by strategy selection of merchants. And perceived risk is influenced by the compensation probability and the positivity of platform's supervision. So smart contract has a substitution effect on the honest behavior of merchants and the supervision of platform. Merchants' decisions are influenced by the expected punishment and the cost of smart contract, as well as by decisions of consumers.

\subsubsection{Analysis on the evolutionary stability}

According to the research of Ritzberger and Weibull [22], 5 asymptotic stability points are obtained by calculating the equations $\quad \begin{aligned} & F(x)=0 \\ & F(y)=0\end{aligned}$, namely $A(0,0), B(0,1), C(1,0), D(1,1), E\left(x^{*}, y^{*}\right)$, $x^{*}=\frac{C_{3}-W}{\left(b_{2}-b_{1}\right) C_{2}-(1-\lambda)(r P-\beta \mathrm{H})}, y^{*}=\frac{a_{2} C_{1}-[\lambda+(1-\lambda) \beta] r P}{\left(a_{2}-a_{1}\right) C_{1}+r P-[\lambda+(1-\lambda) \beta] r F}$. The Jacobi matrix $\mathbf{J}$ a of this system can be obtained.

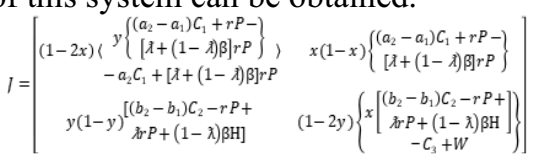

If the determinant of the corresponding matrix of the equilibrium point $\operatorname{det}>>0$, and the trace of the determinant $\operatorname{tr}<0$, this point is the evolutionary-stable strategy ESs. If trace $t r=0$, it is the saddle point. According to the asymptotic stability analysis above, if the perceived utility loss $r P$ is less than the cost of applying for aftersales service $a_{1} c_{1}$, the consumer will not apply for aftersales service. Therefore, assuming that $a_{1} c_{1}<r P$.

Table 2: Judgement of Equilibrium Points

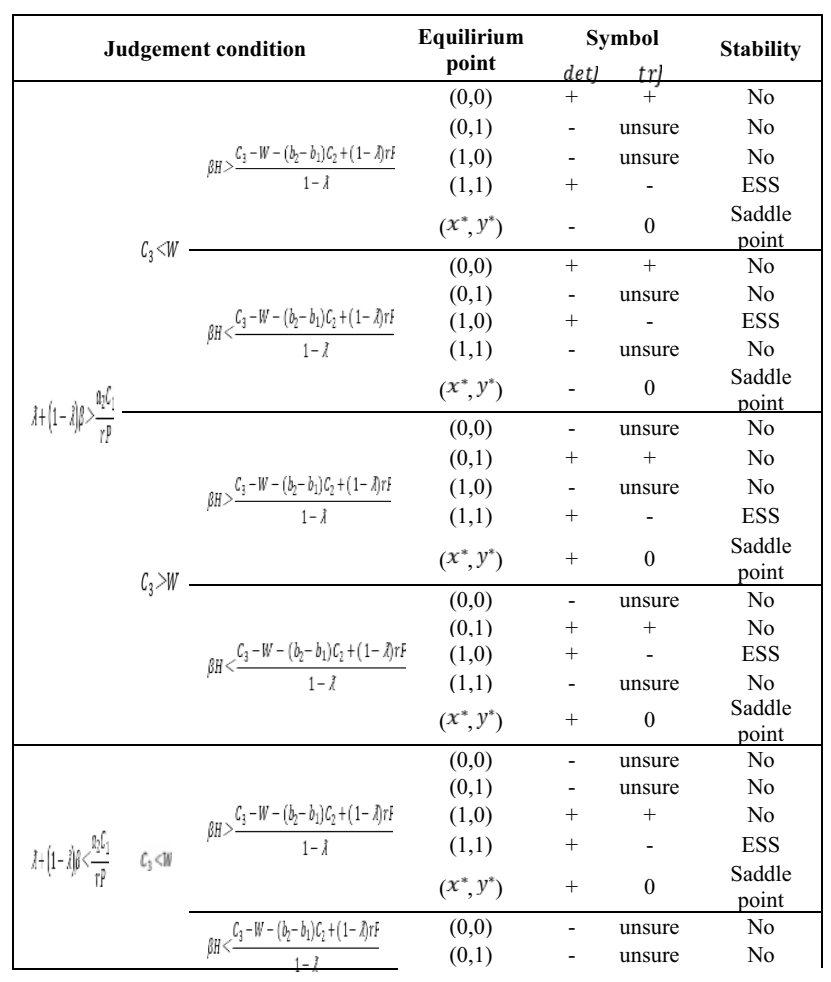

a Jacobi matrix of this system is as follow:

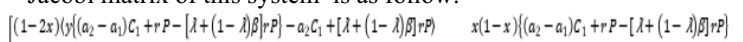
$y(1-y)\left[\left(b_{2}-b_{1}\right) c_{2}-(1-\lambda)(r p-\beta H)\right]$

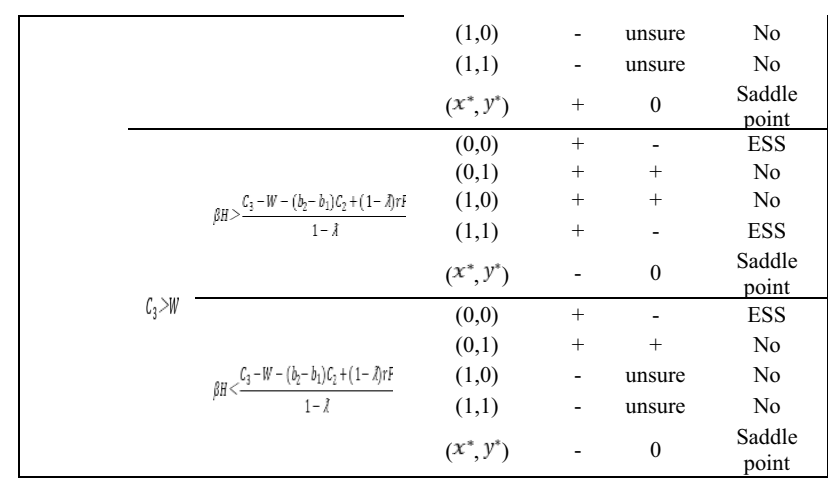

And then, the evolutionary stability strategy is determined according to the determinant det] and trace $t r$ ] of Jacobi matrix J. The results are shown in Table 2.

According to Table 2, let's analyze the 7th case as an example. When $x+(1-x) \beta<\frac{a_{2} C_{1}}{r P}, C_{3}>W, \beta H>\frac{b_{1} C_{2}+C_{3}-W+r P-b_{2} C_{2}-\lambda r F}{1-\hbar}$, there are two ESS points of $A(0,0)$ and $D(1,1)$, unstable points of $B(0,1)$ and $c(1,0)$, and saddle point of $E\left(x^{*}, y^{*}\right)$. In other words, if the perceived risk of consumers is relatively high, the cost of using smart contract is more than the potential income, and the supervision is strong, the final choices of consumers and merchants were (applying for aftersales service, using smart contract) and (not applying for after-sales service, not use smart contract).

Assuming that the initial state is $c(1,0)$, if merchants does not use smart contract at this time, consumers would choose not to apply for after-sales service because of the high perceived risk, and the punishment imposed on merchants would also be reduced with the change of consumer behavior. So merchants would continue to choose not to use smart contract, the final state will become $A(0,0)$. If merchants choose using smart contract at this time, consumers would continue to apply for aftersales service because of the reduction of perceived risk and cost, the final state will become $D(1,1)$.

Assuming that the initial state is $B(0,1)$, if the merchants choose not to use smart contract at this time, consumers, perceiving the increase of after-sales risk and cost, will still keep the option of not applying for aftersales service, and the final state becomes $A(0,0)$. If merchants keep the choice of using smart contract, consumers, combined with the low-risk and low-cost service guarantee, will finally choose to apply for aftersales service, and the final state becomes $D(1,1)$. The evolution diagram of this situation is shown in Figure 1.

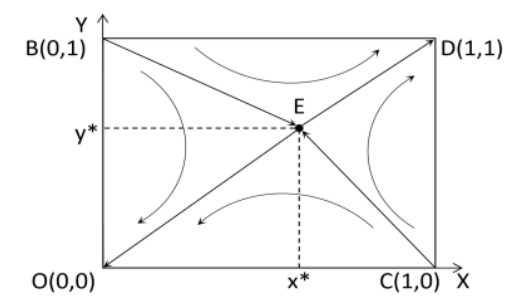

Figure 1 Evolution Diagram of Condition 7

\section{CONCLUSIONS AND SUGGESTIONS}

Under the constraints of income, punishment, positivity of regulatory platform and fraudulent behavior of both 
parties, when both parties are fully honest, even if the platform is negatively regulated, consumers will tend to apply for after-sales service. When merchants commit fraud to a certain extent, the behavior strategies of both parties will be affected by the behaviors of regulatory platform and the other party.

If merchants use smart contracts to reduce consumers' perceived risks and costs, consumers will be more active in applying for after-sales services. However, merchants' decisions are affected by costs and penalties. If the regulations of platform are passive and the punishments are not enough, merchants will continue to maintain their fraudulent behaviors to reduce the cost of paying for consumers. When the platform supervises actively, if potential benefits of using smart contract outweigh the costs, merchants would choose to use smart contracts and consumers would actively apply for aftersales services. When the cost of using smart contract is high, if consumers do not apply for after-sales service, merchants will not have to face high costs and penalties, so they would not use smart contract. If consumers apply for after-sale service and merchants face high penalties, merchants would choose to face the cost of smart contracts to avoid being punished, so they will choose to use smart contracts.

Therefore, the use of smart contract can effectively reduce consumers' risk perception and after-sales cost, encourage consumers to apply for after-sales service, reduce the supervision cost of the platform, and promote the construction of an honest environment for online shopping. The supervision of the platform is still essential because active supervision and the enhancement of punishment can help reduce the occurrence of fraudulent behaviors of merchants. Based on above conclusions, relevant suggestions are proposed as follows:

First, the platform should strengthen supervision, promote the construction of integrity environment, and reduce the risk of consumers' rights protection. Second, merchants should improve their own credit construction, put an end to the behavior of cheating consumers, improve the degree of information disclosure, and make effective service guarantees to reduce consumers' risk perception. Third, consumers should enhance their awareness of safety and rights protection, not be silent victims, and maintain integrity in transactions. Fourth, accelerate the development and application of blockchain technology in business.

\section{References}

1. Intellectual Research Consulting. 《 Market Consumption Survey and Business Model Analysis Report of China's Consumer Goods Retail Industry in 2020-2026》 [M/CD]. (2019-11-14)

2. Zou Tingting, Tang Qiong, Yang Fen. Solutions to information asymmetry under B2C Business model [J]. Modern intelligence, 2006(08):65-68.

3. Yu Kunzhang, Tian Yaqin. Discussion on the Relationship between Service recovery factors and
Consumer Satisfaction [J]. Modern management Science, 2006, 000(006):55-57.

4. Hirschman A O . Exit, Voice, Loyalty: Response to Decline in Firms, Organizations and States[J]. Social Forces, 1970, 25(3).

5. Ostrom A L, Iacobucci D . The effect of guarantees on consumers' evaluation of services[J]. Journal of Services Marketing, 1998, 12(5):362-378.

6. Kelli, Bodey, Debra, et al. Contrasting "complainers" with "non-complainers" on attitude toward complaining, propensity to complain, and key personality characteristics: A nomological look[J]. Psychology \& Marketing, 2007.

7. Hogreve J, Gremler D D . Twenty Years of Service Guarantee Research: A Synthesis[J]. Journal of Service Research, 2008, 11(4):322-343.

8. Jin Liyin. The influence of Service guarantee on customer satisfaction expectation and behavior Tendency -The media effect of risk perception and value perception $[\mathrm{J}]$. Management of the world, 2007 (08): 104-115.

9. Smith, A. K. An experimental investigation of customer reactions to service failure and recovery encounters: Paradox or peril [J]. Journal of Service Research, 1998, 1(1):65-81.

10. Tang Jiansheng, Jia Huimin, Wang Yanyan. Research on consumers' Response to third-party Service Failure based on attribution theory [J]. Industrial engineering and management, 2017, 022(003):172-177.

11. Singh, Jagdip. Consumer Complaint Intentions and Behavior Definitional[J]. Journal of Marketing, 1988, 52(1):93-108.

12. Su Fujin. Industry Credibility and After-sales Guarantee into the bottleneck of development of 2009 Online Shopping Complaints Inventory [J]. Consumer electronics, 2010(2):70.

13. Zeng Yan, Zhu Zhipeng, Zhu Juping, et al. Investigation and Research on after-sale service of Online shopping for College Students [J]. Consumer economy, 2012(05):88-90.

14. Mccollough M A, Gremler D D . A conceptual model and empirical examination of the effect of service guarantees on post-purchase consumption evaluations[J]. Managing Service Quality An International Journal, 2004, 14(1):58-74.

15. Liden S B, Skalen P. The effect of service guarantees on service recovery[J]. International Journal of Service Industry Management, 2003, 14(1): 36-58.

16. Wirtz J , Kum D . Designing Service Guarantees Is Full Satisfaction The Best You Can Guarantee?[J]. Journal of Services Marketing, 2000, 15(4):282-297.

17. Hart, C W L.The power of unconditional service guarantees $[\mathrm{J}]$.Harvard Business Review, 1988,(4):54-62.

18. Ostrom, A L, and Hart, C W L. Service guarantee: Research and practice[A]. in Swartz, T A, and D 
Iacobucci(Ed s.). Hand book of service marketing and management[C]. California: Sage Publications, Inc, 2000:299-316.

19. Bian Xinning, Zhou Jing, Sun Ximin, et al. Hybrid Intelligent Contract Application based on Block chain and third Party [C]// Eco-Connected Digital Power -- proceedings of the 2019 Annual Conference on Power Industry Informatization. 2019.

20. Buterin V. A next-generation smart contract and decentralized application platform.[EB/OL]. [201707-

19].https://github.com/ethereum/wiki/wiki/WhitePaper

21. He Haiwu, Yan 'an, Chen Zehua. Review of intelligent Contract Technology and Application based on Block Chain [J]. Computer research and development, 2018, 55(11):112-126.

22. Ritzberger K, Weibull J W. Evolutionary selection in normal-form games[J]. Econometrica, 1996, 63(6):1371-1399. 